\title{
Hurthle Cell Adenoma and Papillary Microcarcinoma in Thyroid: Collision Tumors
}

\author{
${ }^{1}$ Chanchal Rana, ${ }^{2}$ Niraj Kumari
}

\section{ABSTRACT}

The combination of more than one thyroid carcinoma variants has been reported very rarely which includes combination of follicular carcinoma with papillary carcinoma, medullary carcinoma with follicular carcinoma and anaplastic, and follicular and papillary carcinoma with follicular adenoma. We report another combination of Hurthle cell adenoma with incidental occurrence of micropapillary carcinoma adding to the group of collision tumors in thyroid.

Keywords: Collision tumor, Hurthle cell adenoma, Papillary microcarcinoma.

How to cite this article: Rana C, Kumari N. Hurthle Cell Adenoma and Papillary Microcarcinoma in Thyroid: Collision Tumors. World J Endoc Surg 2018;10(2):134-136.

Source of support: Nil

Conflict of interest: None

\section{INTRODUCTION}

The presence of two intimately associated but morphologically distinct neoplasm in thyroid is an unusual phenomenon. Such an occurrence reported in literature so far includes medullary carcinoma with follicular carcinoma ${ }^{1,2}$; medullary carcinoma and papillary carcinoma ${ }^{3,4}$; tall cell variant of papillary carcinoma with Hurthle cell carcinoma ${ }^{5}$; and follicular and papillary carcinoma with follicular adenoma. 6,7 Such tumors are commonly referred to as "collision tumors."

There is no known reported case of coexisting Hurthle cell adenoma which is a variant of follicular adenoma and papillary carcinoma in thyroid gland. We report another collision tumor adding to the literature which is a combination of Hurthle cell adenoma and papillary microcarcinoma occurring in a middle-aged female. This association has not been reported so far in the literature to the best of authors' knowledge.

${ }^{1}$ Assistant Professor, ${ }^{2}$ Associate Professor

${ }^{1}$ Department of Pathology, King George Medical University Lucknow, Uttar Pradesh, India

${ }^{2}$ Department of Pathology, Sanjay Gandhi Postgraduate Institute of Medical Sciences, Lucknow, Uttar Pradesh, India

Corresponding Author: Chanchal Rana, Assistant Professor Department of Pathology, King George Medical University Lucknow, Uttar Pradesh, India, e-mail: chanchal.rana@ lalpathlabs.com

\section{CASE REPORT}

A 45-year-old lady presented with anterior neck swelling for 3 years duration which was progressively increasing in size. There was no history of rapid increase in size, pain over swelling, or any compressive symptoms like change of voice or dysphagia.

On examination, there was a well-defined $8 \times 7 \mathrm{~cm}$ firm swelling that moved with deglutition in right lobe of thyroid. There were no palpable regional lymph nodes, carotid bruit, or retrosternal extension. Trachea was deviated toward left. Rest of the systemic examination was largely unremarkable.

Biochemical investigations showed triiodothyronine of $1.86 \mathrm{nmol} / \mathrm{L}$ (normal range $1.3-2.8 \mathrm{nmol} / \mathrm{L}$ ), thyroxine of $88.7 \mathrm{nmol} / \mathrm{L}$ (normal range $60-180 \mathrm{nmol} / \mathrm{L}$ ), and thyroid-stimulating hormone of $2.76 \mathrm{mIU} / \mathrm{L}$ (normal range $0.3-5 \mathrm{mIU} / \mathrm{L}$ ).

Fine needle aspiration cytology was performed from this nodule before surgery. Smears were cellular and showed clusters as well as dispersed population of Hurthle cells having moderately anisomorphic nuclei with dispersed chromatin, conspicuous nucleoli, and abundant amount of granular cytoplasm. Mitosis and necrosis were absent. With these features, diagnosis of Hurthle cell neoplasm was made.

Patient was admitted for surgery and total thyroidectomy was performed. During surgery, right level 3 lymph node measuring $1 \times 1 \mathrm{~cm}$ was identified, which was subsequently sent for frozen histology and was reported as negative for malignancy. Total thyroidectomy specimen was sent for histopathological examination. On gross examination, the right lobe measured $8.7 \times 7.5 \times 4.5 \mathrm{~cm}$ and left lobe measured $5 \times 2 \times 1 \mathrm{~cm}$. The outer surface of right lobe was bosselated. Cut surface showed the presence of a well-defined nodule that was encapsulated, fleshy, and brownish in color with areas of hemorrhage (Fig. 1A). Left lobe of thyroid was unremarkable. Multiple sections were examined with capsule. Microscopically, the sections showed an encapsulated lesion composed of closely packed follicles displaying mildly an isomorphic nuclei, dispersed chromatin, conspicuous nucleoli at places, and abundant amount of granular eosinophilic cytoplasm (Fig. 1B). Necrosis, mitosis, capsular, and vascular invasion were not seen. One of the sections showed a focus of micropapillary carcinoma located in 


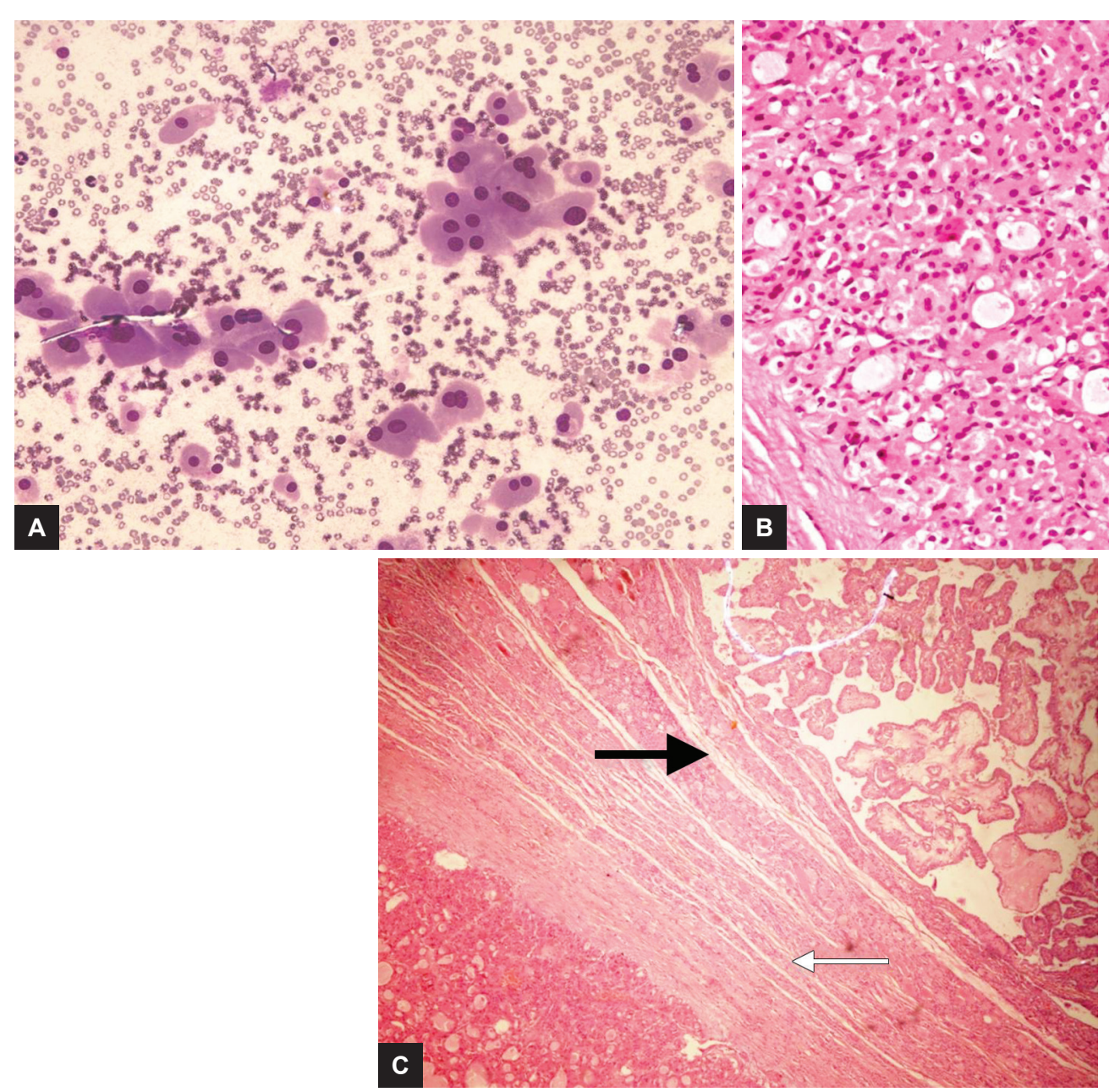

Figs 1A to C: (A) Cytomorphology of Hurthle cell neoplasm (May Grunwald Giemsa stain, 40x): Tumor cells lying singly as well as in groups, displaying anisomorphic nuclei with dispersed chromatin and abundant amount of granular cytoplasm. (B) Histology of Hurthle cell neoplasm (hematoxylin and eosin stain, 40x): Lesions with closely packed variable sized follicles displaying cells with mildly anisomorphic nuclei, dispersed chromatin, and abundant amount of granular eosinophil. (C) Synchronous occurrence of Hurthle cell adenoma (white arrow) and papillary carcinoma (black arrow) (hematoxylin and eosin stain, 20×)

the adjacent thyroid parenchyma outside the capsule of adenoma composed of papillae lined cubo-columnar cells displaying oval overlapping nuclei with nuclear clearing, grooving, and the presence of intranuclear inclusions (Fig. 1C). Therefore, a diagnosis of Hurthle cell adenoma with coexisting papillary microcarcinoma in right lobe was made.

Postoperatively, the patient developed asymptomatic hypocalcemia and was given oral calcium and vitamin D supplementation. At the time of discharge, the wound was clean and healthy and she was normocalcemic.

\section{DISCUSSION}

Thyroid nodules are very common in clinical practice with an estimated prevalence of $5 \%$ by palpation and increasing up to $50 \%$ in elderly individuals after the generalized use of ultrasonography. ${ }^{8}$ The occurrence of any neoplasm in thyroid is usually of a single type. Rarely more than one type of thyroid neoplasm occurs at the same time in single or different lobes. These tumors can occur as mixed tumor, composite tumor, or collision tumors. "Collision tumor" refers to coexistent but independent tumors that are histologically distinct. Collision tumor must be differentiated from mixed and composite tumor which shows follicular and parafollicular-derived cellular elements. Composite tumors have two discrete populations of different cell origin, e.g., follicular and c cell. So, as per these definitions, our case falls in the category of collision tumors. ${ }^{9}$

Cases of composite thyroid carcinomas have been reported in literature. Cases having medullary carcinoma with foci of a differentiated cancer of follicular origin (papillary/follicular) are reported. ${ }^{1,2}$ Similarly, synchronous occurrence of medullary carcinoma with papillary carcinoma has also been reported. ${ }^{3,4}$ There is one report of coexistent Hurthle cell carcinoma and tall cell variant of papillary carcinoma in the same lobe of thyroid gland. ${ }^{5}$ Existence of multiple neoplasms has also been described. Ganguly et $\mathrm{al}^{7}$ have reported synchronous occurrence of anaplastic, follicular, and 
papillary thyroid carcinoma with follicular adenoma in thyroid.

The common follicular histogenesis of Hurthle cell adenoma and papillary carcinoma explains the synchronicity of these two entities in the index case. The gross specimen in our case was sampled extensively to exclude the possibility of any capsular or vascular invasion to rule out Hurthle cell carcinoma; however, incidentally, microscopically, we found a focus of micropapillary carcinoma adjacent to the adenoma capsule. Since the focus of carcinoma was micropapillary and there was no lymph node metastasis, there was no need for adjuvant therapy apart from surgical resection. Had there been a larger component of papillary carcinoma, the patient would have received radioiodine therapy.

In summary, we report a collision tumor comprising of Hurthle cell adenoma and papillary microcarcinoma which has not been reported so far. Although there was no change in the management of this case, follow-up study would throw light on the prognostic behavior of this indolent tumor. The association of benign and malignant lesion may modify the management of patient and may help to provide an adequate management, although it is seen in a minority of patients. Extensive sampling of even in benign appearing thyroid nodules for focus of carcinoma and follow-up studies of such cases would add to the knowledge of prognostic behavior of collision and composite tumors.

\section{REFERENCES}

1. Volante M, Papotti M, Roth J, Saremaslani P, Speel EJ, Lloyd RV, Carney JA, Heitz PU, Bussolati G, Komminoth P. Mixed medullary follicular thyroid carcinoma: molecular evidence for a dual origin of tumor components. Am J Pathol 1999 Nov;155(5):1499-1509.

2. Papotti M, Negro F, Carney JA, Bussolati G, Lloyd RV. Mixed medullary-follicular carcinoma of the thyroid. A morphological, immunohistochemical and in situ hybridization analysis of 11 cases. Virchows Arch 1997 May;430(5):397-405.

3. Sadat Alavi M, Azarpira N. Medullary and papillary carcinoma of the thyroid gland occurring as a collision tumor with lymph node metastasis: a case report. J Med Case Rep 2011 Dec;5:590.

4. Dionigi G, Castano P, Bertolini V, Boni L, Rovera F, Tanda ML, Capella C, Bartalena L, Dionigi R. Simultaneous medullary and papillary thyroid cancer: two case reports. J Med Case Rep 2007 Nov;1:133.

5. Baloch ZW, Mandel S, LiVolsi VA. Combined tall cell carcinoma and Hürthle cell carcinoma (collision tumor) of the thyroid. Arch Pathol Lab Med 2001 Apr;125(4):541-543.

6. Bhargav PR, Gayathri KB. Synchronous occurrence of anaplastic, follicular and papillary carcinomas with follicular adenoma in thyroid gland. Indian J Pathol Microbiol 2011 Apr-Jun;54(2):414-415.

7. Ganguly R, Mitra S, Datta AK. Synchronous occurrence of anaplastic, follicular and papillary carcinomas with follicular adenoma in thyroid gland. Indian J Pathol Microbiol 2010 Apr-Jun;53(2):337-339.

8. Polyzos SA, Kita M, Avramidis A. Thyroid nodules-stepwise diagnosis and management. Hormones (Athens) 2007 AprJun;6(2):101-119.

9. Walvekar RR, Kane SV, D'Cruz AK. Collision tumor of the thyroid: follicular variant of papillary carcinoma and squamous carcinoma. World J Surg Oncol 2006 Sep;4:65. 